\title{
Experimental analysis of frequency on tensile-compressive fretting fatigue behaviour of Al-Zn-Mg alloy
}

\author{
JIANG Jiaxin ${ }^{1, a}$, FU Xuemin ${ }^{2 * b}$ and SHEN Yue ${ }^{3, c}$, Jiang Xiaosong ${ }^{4, d}$ \\ ${ }^{1}$ School of Mechanical Engineering, Chengdu Textile College, Chengdu 611731, P. R. China \\ ${ }^{2}$ School of Mechanical Engineering, Chengdu Textile College, Chengdu 611731, P. R. China \\ ${ }^{3}$ School of Materials Science and Engineering, Southwest Jiaotong University, Chengdu 610031, P. \\ R. China \\ ${ }^{4}$ School of Materials Science and Engineering, Southwest Jiaotong University, Chengdu 610031, P. \\ R. China \\ a573098007@qq.com, bjiangjiaxin2004@126.com, c 1023790153@qq.com, dxs jiang@126.com
}

Correspondence should be addressed to Fu Xuemin, 573098007@qq.com

Keywords: Al-Zn-Mg alloy, frequency, fretting fatigue, fracture

\begin{abstract}
Experimental analysis of frequency on tensile-compressive fretting fatigue behaviour of $\mathrm{Al}-\mathrm{Zn}-\mathrm{Mg}$ alloy was studied in this paper. Effect of frequency on fretting fatigue lives, damage characterization and fretting fatigue fractures of Al-Zn-Mg alloy were researched under different frequencies. Factors affect fretting fatigue life and comparison of lives between fatigue and fretting fatigue were discussed. Average scar widths of Al-Zn-Mg alloy at various frequencies, comparison of fretting scars' oxygen content at various frequency and abrasion loss of Al-Zn-Mg alloy under different frequencies were used to study on influence of frequency on fretting fatigue damage behavior of Al-Zn-Mg alloy. Fretting fatigue crack growth zone in the whole fracture zone were used to study on effect of frequency on fretting fatigue fractures of Al-Zn-Mg alloy.
\end{abstract}

\section{Introduction}

Fretting fatigue is a destruction process of occurring between two contact surfaces having small-amplitude oscillatory motion, it can be described as a combination of two concomitant processes: wear and fatigue [1-3]. Fretting fatigue widely lies in machine component, mainly happen in interfaces which bearing alternating load. Fretting will precipitate the fatigue crack early initiation and accelerate crack growth on the surface, finally lead to components failure in much lower than the material fatigue limit, even lower than the elastic limit, significantly reduce the fatigue life of the component, indeed cause catastrophic accidents[1-3]. This study is mainly aimed at lightweight materials Al-Zn-Mg alloy, which is widely used in automobile, rail transit engineering field, etc[4-6]. The tension/compression fretting fatigue test of Al-Zn-Mg alloy under different frequency would be carried out, and fretting fatigue performances were characterized by the fretting fatigue life, fretting damage zone and fracture morphology.

\section{Experimental procedure}

In this study, material mechanics performance is investigated by adopting the method of static tension; the microstructure of the original sample was observed by metallographic microscope, the analysis of the influence of microstructure on mechanical properties of the material and determination whether there are defects were performed. Fretting fatigue test material used in the experimental is Al-Zn-Mg alloy which are shown in literature [7]. MTS809 axial/torsional electro-hydraulic servo system conduct tension/compression fretting fatigue test was used to analyze effect of frequency on the fretting fatigue life. When the other conditions maintain unchanged, specimens were subjected to five different frequencies from $3 \mathrm{~Hz}$ to $15 \mathrm{~Hz}$. These experiments are 
conducted based on cyclic stress controlled at equivalent stress amplitude of 252MPa, a sine wave form and a stress ratio of -1, $200 \mathrm{MPa}$ Hertz contact stress imposed by fretting bridge, in lab air at temperatures of $22{ }^{\circ} \mathrm{C}$ and relative humidity of $40 \%$ [7]. Scanning electron microscope (SEM, Quanta 200 FEG-SEM) was used to analyze the fretting damage zone and fatigue fracture, then to determine the related mechanism.

\section{Results and discussion}

\section{Effect of frequency on tensile-compressive fretting fatigue lives of Al-Zn-Mg alloys.}

Fretting fatigue lives of Al-Zn-Mg alloy at various frequencies are shown in Fig.1. As can be seen from Fig.1, fretting fatigue lives variation of Al-Zn-Mg alloy was not linear with frequency. At lower frequencies (less than $9 \mathrm{~Hz}$ ), fretting fatigue life decreases with increase of frequency. When the life drops to a critical value (corresponding to $9 \mathrm{~Hz}$ ), fretting fatigue life increases with increase of frequency. The variation law of fretting fatigue life can be explained according to characteristics of fretting fatigue area theory. Different frequency will lead to contact surface of different friction (friction coefficient), and friction force is different to make the surface contact area wear and fretting area property (adhesive zone, mixed zone, slip zone) difference. The relative sizes of the three zones are different in the fretting zone so that the possibility of fatigue crack initiation is small, eventually it can lead to different fretting fatigue life [8]. According to the fretting map, the mixed zone (between the slip region and the adhesive zone) is the most easily crack initiation and propagation region to decrease fretting fatigue life. When frequency is very low, contact surface friction is large and fretting wear area is easy to be in the state of adhesion. In this way can lead to small adhesion zone, big mixing zone and slip zone in which fatigue crack is not easy to crack initiation and propagation so that fretting fatigue life is high. When the frequency gradually increases, friction force on the contact surface decreases and the fretting wear zone is changed from adhesive zone to slip zone to reduce the adhesion area. The mixing zone and the slip zone increase, so the possibility of crack initiation and propagation is increased to decrease fretting fatigue life. But when the frequency is more than $9 \mathrm{~Hz}$, with the increase of frequency, the same life span of time is shortened because oxidation effect is small and less oxidation wear debris formed in the contact area. Wear debris movement speed increase and wear debris easily overflow contact surface to reduce the third body (oxidative wear debris) in the contact area. The role of wear debris buffer decreased and frictional force increases so that the wear zone is changed from slip zone to adhesive zone. The mixed zone and the slip region decreased and fretting fatigue life has increased.

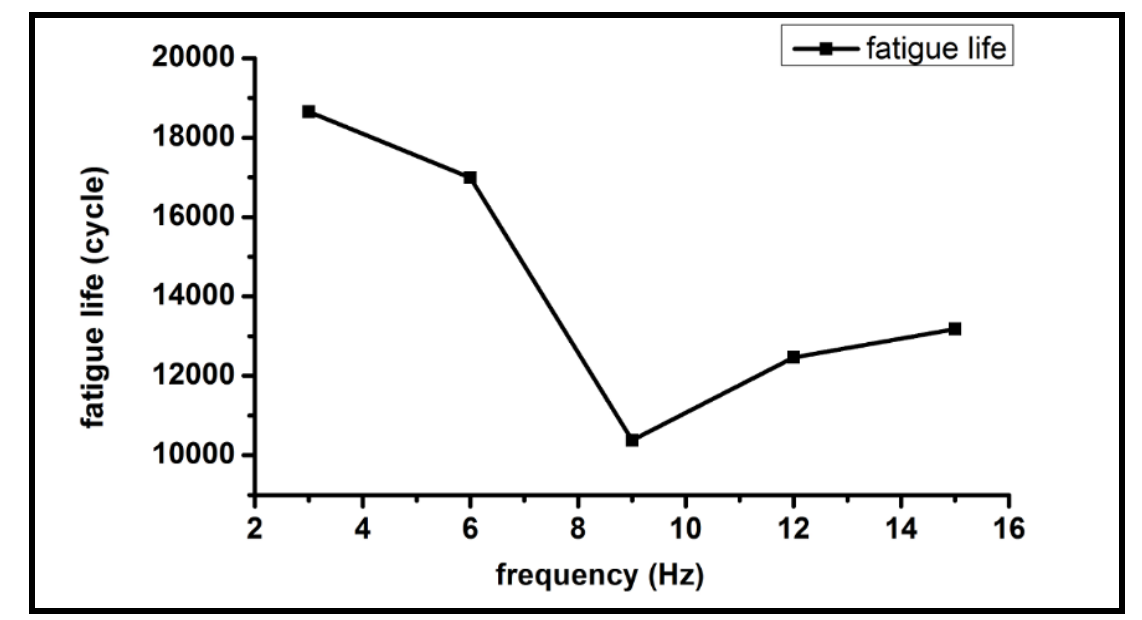

Fig.1 Fretting fatigue lives of Al-Zn-Mg alloy at various frequency

The frequency of $9 \mathrm{~Hz}$ was used as a representative of tensile-compressive fretting fatigue test. According to Table 1, it can be seen that there is a significant difference in the life of tensile-compressive fretting fatigue and fatigue life. When the other conditions are the same, under the condition of frequency $9 \mathrm{~Hz}$, tensile-compressive fretting fatigue life is reduced by about $98 \%$ 
compared with the ordinary fatigue life. This shows that fretting fatigue greatly reduces the fatigue life of Al-Zn-Mg alloy. There are two factors that affect the fatigue life of fretting: (1) Fretting can cause contact surface area to be repeated wear and tear, and the wear and tear parts cannot be repaired so that the fresh matrix is constantly being worn and oxidized. Serious stress concentration can be caused in the contact area which not only reduce the fatigue strength of the material, but also fatigue crack initiation and propagation can be easily made in this place, thereby the fatigue life can be greatly reduced [9]. (2) Due to the fretting fatigue surface adhesion, delamination, oxidation, corrosion pit formation can be formed in the fretting zone which can cause serious stress on the boundary between sliding zone and adhesion zone so that fatigue crack initiation is easy in this place. Fretting fatigue crack early propagation happens and combined action of micro cracks under cyclic stress and surface shear stress appears[10]. Therefore, early extension of fretting fatigue crack emerges and speed is much faster than ordinary fatigue crack so that the fretting fatigue life is lower than the ordinary fatigue life.

Table 1 Comparison of lives between fatigue and fretting fatigue $(9 \mathrm{~Hz})$

\begin{tabular}{lccc}
\hline & Frequenc & Contact stress pressure & Fatigue lives/cycle \\
& & & \\
\hline Fatigue & $9 \mathrm{~Hz}$ & $0 \mathrm{MPa}$ & 621718 \\
\hline Fretting Fatigue & $9 \mathrm{~Hz}$ & $180 \mathrm{MPa}$ & 10374 \\
\hline
\end{tabular}

\section{Effect of frequency on tensile-compressive fretting fatigue damage characterization of Al-Zn-Mg alloy.}

The relationship between average fretting scar widths of Al-Zn-Mg alloy and various frequencies are shown in Fig.2 and Fig.3. Can be seen from Fig.2, the diameter of fretting spot increases with the increase of frequency firstly then increase to a critical value (corresponding to $9 \mathrm{~Hz}$ ). With the increase of frequency after $9 \mathrm{~Hz}$, fretting scar widths decreased. Combined with fatigue life-frequency curves can be seen, effect of frequency on fretting scar widths is opposite to the fatigue life and the trend of the curve is just the opposite. According to the reference [11], different frequencies will make different surface friction coefficient, when the frequency is less than $9 \mathrm{~Hz}$, maximum friction decreases with increasing frequency so that the fretting resistance decreases with increase of the fretting range which can lead to formation of fretting scar widths increases. When the frequency is greater than $9 \mathrm{~Hz}$, the frequency increases and the time of the same life experience is much shorter which can causes effect of oxidation is less than that of the contact area. And the oxidation wear debris movement speed increase, the wear debris is easy to overflow the contact surface resulting in the third body reduction of the contact area. The role of wear debris buffer decreased to increase friction and increase of the resistance caused by fretting decreases the range of fretting to decrease fretting scar widths.

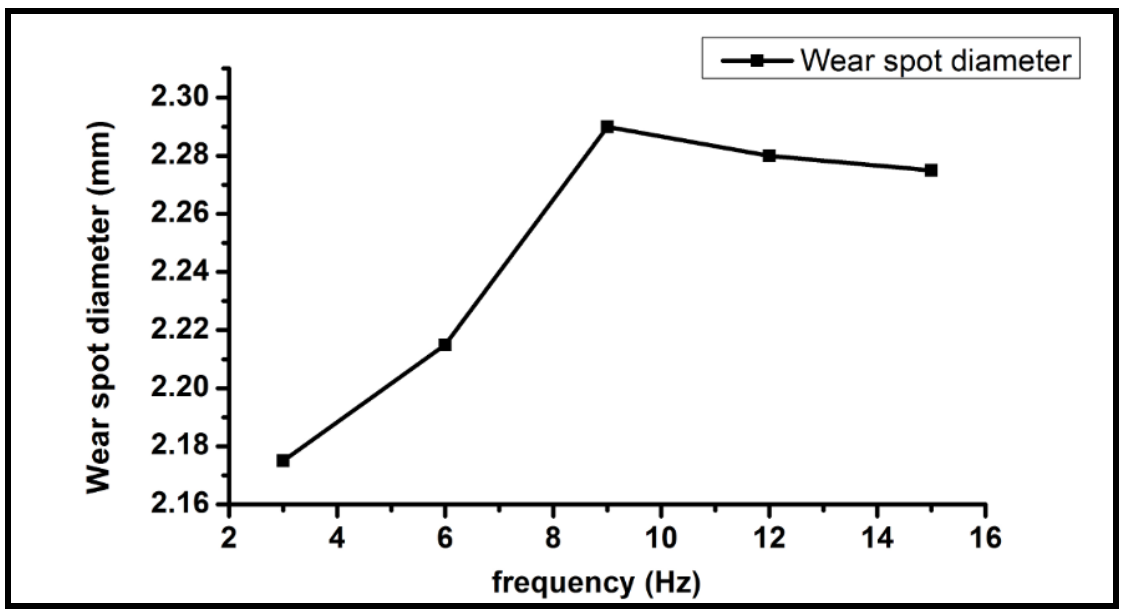

Fig.2 Average scar widths of Al-Zn-Mg alloy at various frequency 
Fretting scars morphology and fretting scars' oxygen content provides an important basis for fretting fatigue damage mechanisms. According to the morphology of fretting scars can be seen in the frequency of $3 \mathrm{~Hz}$ fretting scars' center area is the most smooth while its edge area is serious because the fretting wear is more serious which can be seen in Fig.3. In the fretting process, surface material of fretting fatigue area is firstly removed, then, in the repeated rolling and oxidation process, it becomes a granular oxidized abrasive particle[12]. Therefore, it can be judged that fretting wear is more serious and more oxide wear debris, then its oxygen content will be higher. Then the fatigue crack initiation and propagation in this place is easy to be extended. According to fretting fatigue area topography can be roughly estimated: The center area of fretting fatigue area center with frequency of $9 \mathrm{~Hz}$ is lower than that of the central region of the other two frequencies, but the oxygen content in the edge area is higher than that of the other two frequencies. When the frequency is $3 \mathrm{~Hz}$ and $15 \mathrm{~Hz}$, fretting fatigue area morphology is very similar, the central region and the edge region of fretting fatigue area are not quite different from the wear degree. The oxygen content in their central and marginal areas should be slightly different, this is consistent with the final component analysis which can be seen in Table 2 .

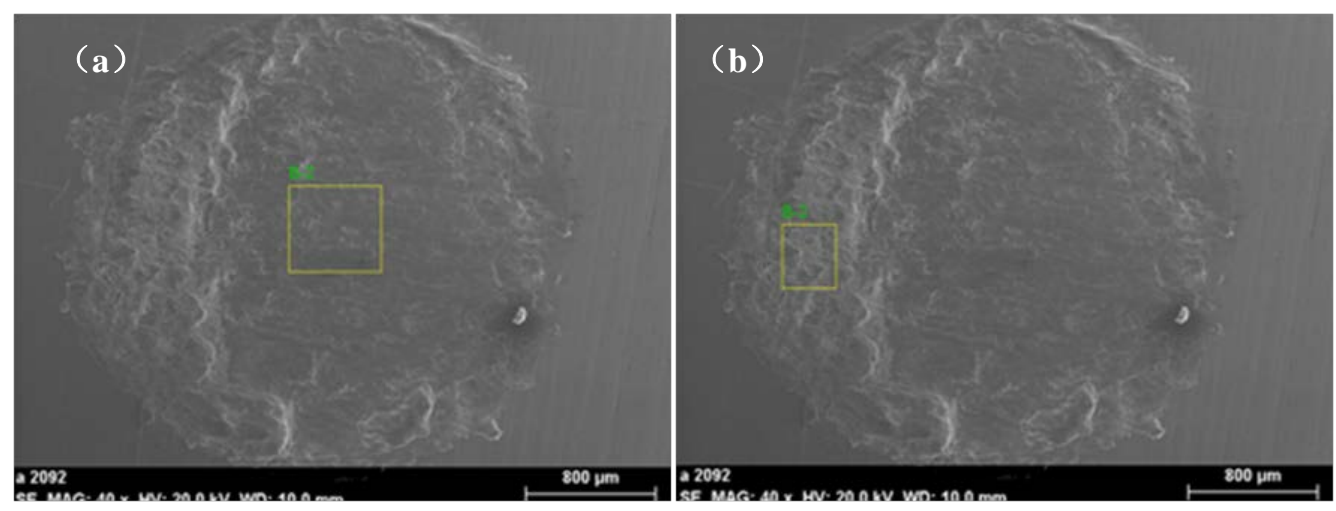

Fig.3 SEM results of the fretting scars

(a)Morphology (3 Hz), (b)Edge(3 Hz)

Table 2 Comparison of fretting scars’ oxygen content at various frequency (wt\%)

\begin{tabular}{lcc}
\hline \multicolumn{1}{l}{ Frequenc } & center oxygen content & edge oxygen content \\
$\mathrm{y}$ & & \\
\hline $3 \mathrm{~Hz}$ & 9.94 & 31.15 \\
\hline $9 \mathrm{~Hz}$ & 1.08 & 41.39 \\
\hline $15 \mathrm{~Hz}$ & 8.03 & 30.24 \\
\hline
\end{tabular}

After fretting fatigue test, abrasion loss of Al-Zn-Mg alloy under different frequencies is shown in Table 3. As can be seen in Table 3, the wear rate decreases with the increase of frequency, although wear at lower frequency and higher frequency will remain unchanged, but the overall trend is that the wear rate decreases with the increase of frequency. The effect of frequency is the chemical factor and chemical processes are related to time. In an inert environment without chemical reaction, there is no effect of frequency. Because this experiment is carried out in the laboratory at room temperature, there is no inert gas protection, so it will be affected by frequency. Dobromirski [11] thinks that frequency is different so that the surface friction coefficient is different. When contact loading is determined, the friction force is proportional to coefficient of friction. Therefore, the larger friction coefficient corresponds to friction between the contact surfaces. In the same case as other conditions (for example, the same contact pressure), low frequency, greater friction, and as the frequency increases, the maximum frictional force will fall, so that loading cycles to achieve maximum friction is increased. No matter what kind of wear mechanism in fretting process, when measuring friction force is large, its fretting damage is also large. In addition, the degree of wear is also related to the oxidation, when frequency is low, the wear of Al-Zn-Mg alloy in a fretting fatigue cycle is large, and 
the corresponding fatigue life is long which can lead to long period of motion, so that the total amount of wear is high. In this way can explain that the wear rate decreases with the increase of frequency.

Table 3 Abrasion loss of Al-Zn-Mg alloy under different frequencies

\begin{tabular}{ccccc}
\hline NO. & Stress amplitude & Contact stress pressure & $\begin{array}{l}\text { Frequenc } \\
\mathrm{y}\end{array}$ & Abrasion loss \\
& & & & \\
\hline 1 & $252 \mathrm{MPa}$ & $180 \mathrm{MPa}$ & $3 \mathrm{~Hz}$ & $0.05 \mathrm{~g}$ \\
\hline 2 & $252 \mathrm{MPa}$ & $180 \mathrm{MPa}$ & $6 \mathrm{~Hz}$ & $0.05 \mathrm{~g}$ \\
\hline 3 & $252 \mathrm{MPa}$ & $180 \mathrm{MPa}$ & $9 \mathrm{~Hz}$ & $0.04 \mathrm{~g}$ \\
\hline 4 & $252 \mathrm{MPa}$ & $180 \mathrm{MPa}$ & $12 \mathrm{~Hz}$ & $0.03 \mathrm{~g}$ \\
\hline 5 & $252 \mathrm{MPa}$ & $180 \mathrm{MPa}$ & $15 \mathrm{~Hz}$ & $0.03 \mathrm{~g}$ \\
\hline
\end{tabular}

Effects of frequency on tensile-compressive fretting fatigue fractures of $\mathrm{Al}-\mathrm{Zn}-\mathrm{Mg}$ alloy.

Fig.4 illustrates that fretting fatigue fracture can be divided into three zones: crack initiation, propagation and final fracture. From fretting fatigue fracture morphology, it has maximum brightness of fretting fatigue source area because of the constant friction and extrusion of the cross section during the whole crack growth process to show bright smooth. In a fretting fatigue fracture, fatigue sources are generally on the surface of the specimen which can have one or more and connected with notch crack, marks, pits and other defects due to fretting fatigue because the stress concentration will cause fatigue cracks. Fatigue propagation zone is a fracture region formed by the fatigue crack growth and the region is an important characteristic of fretting fatigue fracture [13]. In this experiment the fretting characteristics of the region is relatively smooth and fracture distribution of shell ridge and the smooth surface of the region is a continuation of crack initiation region. The final fracture region is the fracture region formed by the rapid expansion of the last crack of the crack. In the metastable extension of fretting fatigue crack growth, with the constant stress cycle, crack size is growing. When the crack grows up to the critical size of $\alpha_{c}$, fracture toughness $K_{I C}\left(K_{C}\right)$ was achieved by the stress field intensity factor $\mathrm{K}_{\mathrm{I}}$ at the crack tip (or the stress concentration at the crack tip reaches the breaking strength of the material), then the crack is fast expanding to lead to the final fracture of the material. Effects of frequency on fretting fatigue fractures of Al-Zn-Mg alloy lie in fretting fatigue crack growth zone in the whole fracture zone. Higher frequency, the greater the proportion of fatigue crack growth zone exits in the whole fracture zone. This is related to the fatigue crack growth rate, a large number of studies show that $[14,15]$, when the amplitude of the stress intensity factor of the crack tip is lower, basically it was unaffected by loading frequency. When the amplitude of the stress intensity factor of the crack tip is larger, load frequency has a greater impact on the distance of crack propagation. It can be seen from Fig.4, fretting fatigue crack initiation roots in directly from the bottom of fretting spot. After generation of fatigue crack initiation, crack expands sradial (fluvial) to the substrate, this shows that the initial crack growth is mainly in the role of surface shear stress (friction). At the beginning of the fracture surface of the specimen, there are many crack initiation points to form a number of fatigue fretting cracks, but there is a main crack which brings together some of the nearby cracks to form a macroscopic crack extending into the specimen. There are two fatigue sources formed on the surface of the specimen, the corresponding fatigue crack growth region extends along the opposite surface and is perpendicular to the surface of the specimen. Until the two crack growth regions meet to form the final fracture and it is located at the center of the specimen. 

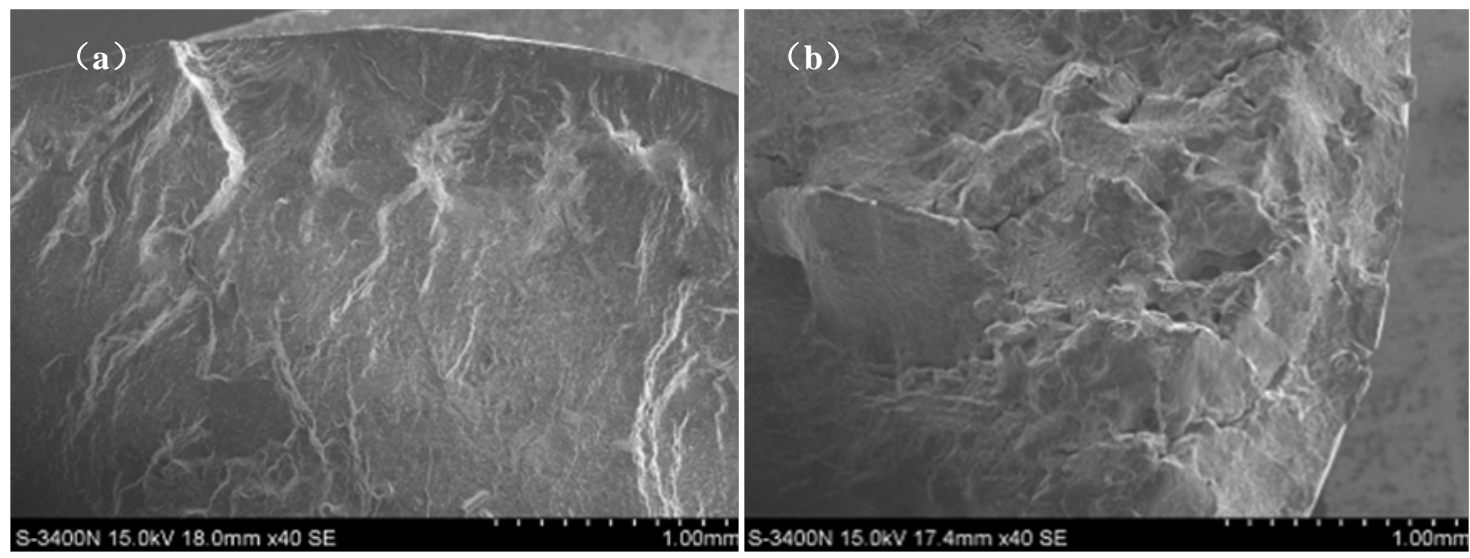

Fig.4 SEM results of fretting fatigue fracture:

(a)Crack initiation $(9 \mathrm{~Hz})$, (b) Final fracture $(9 \mathrm{~Hz})$

\section{Summary}

1) In the process of frequency changing from $3 \mathrm{~Hz}$ to $15 \mathrm{~Hz}$, fretting fatigue life firstly declined with the increase of the frequency, falling to the critical value, again rose with the increase of the frequency. Fretting fatigue greatly reduces the fatigue life of Al-Zn-Mg alloy.

2) In the process of frequency changing from $3 \mathrm{~Hz}$ to $15 \mathrm{~Hz}$, wear extent decreased with the increase of the frequency, fretting scars diameter increased with the increase of the frequency, after increasing to the critical value, again fell with the increase of the frequency.

3 ) In the process of frequency changing from $3 \mathrm{~Hz}$ to $15 \mathrm{~Hz}$, fretting fatigue have more than one fatigue source(fatigue crack initiation site), fracture morphology is consisting of fatigue crack initiation 、 creak propagation and final fracture, effect of frequency on fretting fatigue fractures of $\mathrm{Al}-\mathrm{Zn}-\mathrm{Mg}$ alloy lies in fretting fatigue crack growth zone in the whole fracture zone.

\section{Acknowledgments}

The authors are grateful to the National Natural Science Foundation of China (51201143) for financial support of this work.

\section{References}

[1] Nowell D, Dini D, Hills D A:Engineering fracture mechanics Vol.73(2) .(2006) p. 207

[2] Hills D A. :Wear Vol.175(1) .(1994) p. 107

[3]Vincent L, Berthier Y, Dubourg M C, et al. :Wear Vol.153(1) .(1992) p. 135

[4] Lukasak D A, Hart R M. :Light Metal Age Vol.49(9-10) .(1991) p. 11

[5] Tanner D A, Robinson J S: Experimental mechanics Vol.40(1).(2000) p. 75

[6]Wloka J, Hack T, Virtanen S: Corrosion science Vol. 49(3) .(2007) p. 1437

[7] Jiang Xiaosong, He Guoqiu, Liu Bing, Liu Xiaoshan: Vol.41.(2012) p.136

[8] Vingsbo O, Söderberg S.:Wear Vol. 126(2) .(1988) p.131

[9] Vincent L, Berthier Y, Dubourg M C: Wear Vol. 153(1) .(1992) p. 135

[10] Zhou Z R, Vincent L:Wear Vol.181.(1995) p. 531

[11] Attia M H. :Astm International, 1992.

[12] Lu D, Celis J P, Kenzari S:Wear Vol.270(7) .(2011) p. 528 
[13] Fouvry S, Kapsa P, Vincent L: Wear Vol.195(1) .(1996) p. 21

[14] Zhang you-hong, Lu guo-zhi,Li zhong: Acta Aeronautica et Astronautica Sinica Vol.28(2) .(2007) p. 332

[15] Li Qiang,ZhouChangyu,Huang Wenlong:Journal of nanjing university of chemical technology Vol. 22(1) .(2000) p. 32 